\title{
Investigation of Leisure Time Attitude of University Students According to Some Parameters (Example of Northern Cyprus)
}

\section{Mehmet Sukru Rona ${ }^{1}$ Ali Emre Erol ${ }^{2}$}

'Department of Sport Management, School of Physical Education and Sport, Cyprus International University, Nicosia, Cyprus.

Email:sukrurona@gmail.com Tel:05323527982

${ }^{2}$ Department of Trainer Education, School of Physical Education and Sport, Cyprus International University, Nicosia, Cyprus.

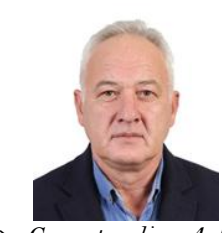

( Corresponding Author)

Abstract

The attitude of leisure can be defined as all the emotions, thoughts, attitudes and behaviors shown for the leisure concept. The aim of this study is to examine the leisure attitudes of the students of the Cyprus University according to various parameters such as gender, age, class, faculty and whether to do recreational sports. A total of 265 students participated in the study. Leisure Attitude Scale was used to evaluate student's leisure attitudes. Independent sample $t$ test was used for analyzing gender and recreational sports variables, and the one-way ANOVA test was used for analysis of age, class and faculty variables. According to the results obtained, there was a significant difference in the cognitive, affective and behavioral dimensions of the three subdimensions of the scale for the variable of doing recreational sports. In addition, differentiation was observed in the cognitive sub-dimension for the age variable and the behavioral subdimension for the class variable.

Keywords: Leisure, Leisure time attitude, Sports, Recreative sports, Cognitive, Affective, Behavioral

Citation | Mehmet Sukru Rona; Ali Emre Erol (2020). Investigation of Leisure Time Attitude of University Students According to Some Parameters (Example of Northern Cyprus). Asian Journal of Education and Training, 6(3): 479-483. History:

Heceived: 29 April 2020

Revised: 10 June 2020

Accepted: 6 July 2020

Published: 20 July 2020

Licensed: This work is licensed under a Creative Commons

Attribution 3.0 License $(\mathrm{cc})$ E

Publisher: Asian Online Journal Publishing Group
Acknowledgement: Both authors contributed to the conception and design of the study.

Funding: This study received no specific financial support.

Competing Interests: The authors declare that they have no conflict of interests.

Transparency: The authors confirm that the manuscript is an honest, accurate, and transparent account of the study was reported; that no vital features of the study have been omitted; and that any discrepancies from the study as planned have been explained.

Ethical: This study follows all ethical practices during writing.

\section{Contents}

1. Introduction

2. Method 


\section{Contribution of this paper to the literature}

The aim of the research is to add innovation to the literature regarding leisure time attitudes. In the selected sample, it is thought that it has contributed to the literature since no research has been done on this subject before. It is thought that it will help to work on leisure time habits.

\section{Introduction}

Leisure time is defined as after meeting the basic needs of individuals and when they are interested in an activity they want (Andersen, Schnohr, Schroll, \& Hein, 2000). People can rest at this time as they wish, have fun, take time to develop themselves or spend time with their loved ones. Many factors are effective in creating personal leisure time. These may be economic, social or psychological factors (Lee et al., 2014) Personal development, fun and rest are leisure functions (Kim, Newton, Sachs, Giacobbi, \& Glutting, 2011).

Leisure attitude has a different definition from the concept of leisure and contains all the individual's feelings, thoughts and attitudes towards leisure and recreation activities (Teaff, 1975). Individuals shape their attitudes to leisure through watching, witnessing and learning. As a result, positive or negative patterns in leisure grow (Marshall, 1999). It has a dynamic structure, that is, they change constantly. These attitudes appear to be parallel to changing individual characteristics (Sheriff \& Sheriff, 1996). Leisure attitudes can be listed as cognitive, affective and behavioral (Ragheb \& Beard, 1982).

There is a lot of research in the literature on university students ' attitudes to leisure. For example, Sindik, Andrijasevic, and Curkovic (2009). She performed a study at the University of Zagreb in 2009 exploring the relationship between leisure behaviors that 109 students attended and recreational sports activities. Another example of a research is what Molina-Garcia et al did to the Spanish university students in 2009. In this research, he explored the relationship between recreational behaviors, physical activity, and plans to come. According to the findings of this research, they concluded that individuals who have more positive attitudes and pursue physical activity in their future plans are more positive. Examples of the types of leisure attitudes survey conducted with university students in Turkey are Binbaşığlu and Tuna 's work with Vocational College Students in the Eastern Anatolia Region during 2014. According to the findings of this research, it is seen that there is a significant difference between women in terms of leisure time attitude and sub-dimensions.

Many research (Berg, Warner, \& Das, 2015; Hagger, Chatzisarantis, Culverhouse, \& Biddle, 2003; Momenan, Delshad, Mirmiran, Ghanbarian, \& Azizi, 2011; Rovio et al., 2005) have shown that playing sports actively influences attitudes toward leisure (Ali Selman Ozdemir, 2020; Ozdemir \& Ayyıldız Durhan, 2020). In the literature, successful acting is called leisure activities. Recreative activities are a variable that affects academic success (Maeda \& Randall, 2003) awareness (Ruffault, Bernier, Juge, \& Fournier, 2016) and personal development (Rodgers \& Gauvin, 1998). In addition, it protects the mental and physical balance of individuals while having an effect on (Ozdemir, 2020a).

Within the reach of the study, in line with all this information; examine the leisure time attitudes of students at Cyprus International University by gender, class, faculty, age and whether they are doing recreational sports.

\section{Method}

\subsection{Study Group}

In the research, it was examined whether the attitudes of Cyprus International University students with regard to their leisure time differed by gender, age, class, recreational sports and the faculty. 265 volunteers were included in the study, which were chosen by the sampling method. These students are between the ages of 19-21, 22-24 and $25+$. The data was taken from a total of 6 faculties. These faculties can be listed as Faculty of Education, School of Physical Education and Sports, Faculty of Arts and Sciences, Faculty of Health Sciences, Faculty of Social Sciences and Faculty of Engineering. These students are 1st grade, 2nd grade, 3rd grade and 4th grade students. In addition, each participant was informed about whether he was actively involved in sports. Detailed information about the demographic information of the participants is given in Table 1 below.

Table-1. Information on participants' demographic features

\begin{tabular}{|c|c|c|c|}
\hline \multicolumn{3}{|c|}{$\mathrm{N}=(\mathbf{2 6 5})$} & \multirow[b]{2}{*}{$\%$} \\
\hline & Variable & f & \\
\hline \multirow[t]{2}{*}{ Sex } & Male & 154 & 58,11 \\
\hline & Female & 111 & 41,89 \\
\hline \multirow[t]{3}{*}{ Age } & $19-21$ & 84 & 31,7 \\
\hline & $22-24$ & 128 & 48,3 \\
\hline & $25+$ & 53 & 20,0 \\
\hline \multirow[t]{2}{*}{ Recreational Sporting Activity Status } & Yes & 116 & 43,77 \\
\hline & No & 149 & 56,23 \\
\hline \multirow[t]{6}{*}{ Department } & Faculty of Education & 34 & 12,83 \\
\hline & Physical Education and Sports & 65 & 24,53 \\
\hline & Faculty of Art and Science & 30 & 11,32 \\
\hline & Faculty of Health Sciences & 48 & 18,11 \\
\hline & Faculty of Social Sciences & 45 & 16,98 \\
\hline & Faculty of Engineering & 43 & 16,23 \\
\hline \multirow[t]{4}{*}{ Grade } & 1. & 52 & 19,62 \\
\hline & 2. & 54 & 20,38 \\
\hline & 3. & 56 & 21,13 \\
\hline & 4. & 103 & 38,87 \\
\hline
\end{tabular}




\subsection{Data Collection Tools}

For the analysis the demographic form of information generated by the researcher was used. For this type information was obtained on the gender, age, class, faculty of the participants and whether they are doing sports. At the same time, Leisure Attitude Scale (LAS) was used. Measuring tool; it was developed by Ragheb and Beard (1982) and adapted to Turkish by Akgül and Gürbüz (2011). The scale consists of three sub-dimensions: cognitive, affective and behavioral. Total internal consistency coefficient (Cronbach Alfa) of the scale was found as .92. The internal consistency coefficients of the cognitive, affective and behavioral subscales were .81, .92 and .95. The scale consists of 36 questions and has a 5-point Likert structure.

\subsection{Data Analysis}

In order to evaluate the attitudes of the participants about their leisure time, the Leisure Attitude Scale was applied online to the participants due to the Covid-19 pandemic. The SPSS 21.0 program was used to find statistical analysis. Within the framework of the study, the relationship and differences between the measuring instruments and their sub-dimensions and other variables have been attempted to be identified. The findings portion includes major variations extracted from the findings about the analyzes. It has been observed that the data set within the limits specified by George and Mallery (2010) $(-1.5$ and +1.5 ; -2.0 and +2.0$)$ has a normal distribution. Therefore, parametric tests were used in the research. Statistics on normality distribution are shown in Table 2. For the variables of gender and whether to do recreational sports, disconnected samples t-test was applied, while one-way Anova test was used for other independent variables.

Table-2. Normality distribution table.

\begin{tabular}{c|c|c|c|c|c}
\hline \multicolumn{7}{c}{ N=265 } \\
\hline & Mean & Median & sd & Distortion & Kurtosis \\
\hline Cognitive & 47,09 & 50,00 & 12,13 & $-1,39$ & 1,20 \\
\hline Affective & 45,43 & 48,00 & 12,74 & $-1,20$ & 0,70 \\
\hline Behavioral & 42,34 & 45,00 & 12,75 & 0,73 & $-0,22$ \\
\hline Note: $-1.5<\mathrm{p}<1.5$
\end{tabular}

\section{Results}

Table- 3. T-test findings between leisure attitude scale and gender variable.

\begin{tabular}{l|c|c|c|c|c|c}
\hline Leisure Attitude and Sex & Sex & $\mathbf{n}$ & $\bar{x}$ & $\mathbf{s s}$ & $\mathbf{t}$ & $\mathbf{p}$ \\
\hline Leisure attitude (total) & Female & 111 & 136,70 & 31,80 & 0,73 & 0,467 \\
\hline & Male & 154 & 133,53 & 38,95 & & \\
\hline Cognitive & Female & 111 & 47,83 & 10,81 & 0,84 & 0,401 \\
\hline & Male & 154 & 46,56 & 13,00 & & \\
\hline Affective & Female & 111 & 46,16 & 11,17 & 0,83 & 0,410 \\
\hline & Male & 154 & 44,90 & 13,76 & & \\
\hline Behavioral & Female & 111 & 42,71 & 11,26 & 0,41 & 0,681 \\
\hline & Male & 154 & 42,08 & 13,76 & &
\end{tabular}

Above are the results on the scale of the leisure attitude and statistical comparisons between certain variables. According to Table 3 independent sample $t$ test results, the difference between the attitude score averages of the participants was not statistically significant in terms of gender ( $p>0.05)$.

Table-4. T-test findings between leisure attitude scale and recreational sports.

\begin{tabular}{l|c|c|c|c|c|c}
\hline $\begin{array}{l}\text { Leisure Attitude and } \\
\text { Recreational sports }\end{array}$ & Recreational sports & $\mathbf{n}$ & $\bar{x}$ & ss & t & p \\
\hline Leisure attitude (total) & Yes & 116 & 145,87 & 33,89 & 4,54 & $0,000^{*}$ \\
\hline Cognitive & No & 149 & 126,29 & 35,53 & & \\
\hline & Yes & 116 & 50,16 & 11,04 & 3,78 & $0,000^{*}$ \\
\hline Affective & No & 149 & 44,70 & 12,43 & & \\
\hline & Yes & 116 & 48,59 & 12,21 & 3,66 & $0,000^{*}$ \\
\hline Behavioral & No & 149 & 42,96 & 12,63 & & \\
\hline & Yes & 116 & 47,11 & 12,04 & 5,68 & $0,000^{*}$ \\
\hline Note: $p>0.05$ & No & 149 & 38,63 & 12,07 & & \\
\hline
\end{tabular}

\section{Note: $\mathrm{p}>0.05$}

According to Table 4, the relationship between university students ' attitude towards leisure and the variable of doing or not doing recreational sports and the mean attitude score of two groups doing sports and not doing sports is contrasted with independent samples t testing. The findings indicate that sports performance has a positive impact on attitudes towards leisure.

The relationship between the cognitive sub-dimension of university students' leisure time scale and the variable of doing or not doing recreational sports was explored in the study. The $t$ value obtained shows a considerable difference between the averages. Results show that doing sports has a positive effect on the leisure-attitude scale cognitive subdimension. In the analysis the relationship was examined between the affective sub-dimension of the scale of the leisure time attitude of university students and whether or not to do recreational sports. The $t$ value obtained suggests that there is a large difference between the averages; it has been found that the size of the impact measured is small $(\pi 2=.05)$. The findings show that playing sports has a positive impact on the size of the leisure attitude impacting the affective subscale. In another analysis, it explores the relationship between the behavioral sub-dimension of the scale of the leisure attitude of university students and whether or not they are doing 
recreational sports. The obtained $t$ value indicates that there is a large difference between the averages; it was found that the measured effect size is moderate $(\pi 2=.10)$. The results show that doing sports has a positive effect on the behavioral sub-dimension of the leisure attitude scale.

Table-5. Anova test findings between leisure attitude scale and age variable.

\begin{tabular}{c|c|c|c|c|c|c}
\hline $\begin{array}{c}\text { Leisure Attitude and } \\
\text { Age }\end{array}$ & Age & $\mathbf{n}$ & Mean & sd & F & p \\
\hline Leisure attitude (total) & $19-21$ & 84 & 132,04 & 3,73 & 1,44 & 0,238 \\
\hline & & & & & & \\
\hline & $22-24$ & 128 & 133,06 & 3,38 & & \\
\hline Cognitive & $25+$ & 53 & 142,25 & 4,59 & & \\
\hline & $19-21$ & 84 & 46,17 & 11,59 & 3,07 & 0,048 \\
\hline Affective & $22-24$ & 128 & 46,18 & 13,00 & & \\
\hline Behavioral & $25+$ & 53 & 50,75 & 10,13 & & 0,735 \\
\hline & $19-21$ & 84 & 44,75 & 11,88 & 0,31 & \\
\hline & $22-24$ & 128 & 45,42 & 13,52 & & \\
\hline & $25+$ & 53 & 46,51 & 12,25 & & 0,212 \\
\hline & $19-21$ & 84 & 41,12 & 12,12 & 1,56 & \\
\hline
\end{tabular}

According to Table 5 the difference between the attitudes score averages of the participants was not statistically significant in terms of age $(\mathrm{p}>0.05)$.

Cognitive sub-dimension showed a significant difference between three different age groups. The calculated effect size is low. $\left(\eta_{2}=.02\right)$. According to the LSD test results applied to test which age groups differ from each other, the cognitive dimension point averages of the 25-27 age group (Mean $=50.75, \mathrm{SS}=10.13$ ) for the 19-21 and 22-24 age group (respectively; Ort, $=46.17, \mathrm{SS}=11.59$, Avg. $=46.18, \mathrm{SS}=13)$ is significantly higher $(\mathrm{p}=.031, \mathrm{p}$ $=.021$, respectively). No significant difference was found between the 19-21 age group and 22-24 age group.

Table-6. Anova test findings between leisure attitude scale and faculty variable.

\begin{tabular}{|c|c|c|c|c|c|c|}
\hline $\begin{array}{l}\text { Leisure Attitude and } \\
\text { Faculty }\end{array}$ & Faculty & $\mathbf{n}$ & Mean & sd & $\mathbf{F}$ & $\mathbf{p}$ \\
\hline \multirow[t]{6}{*}{ Leisure attitude (total) } & Faculty of Education & 34 & 135,38 & 35,50 & 1,21 & 0,303 \\
\hline & School of Physical Education and Sports & 65 & 136,78 & 41,50 & & \\
\hline & Faculty of Arts and Sciences & 30 & 120,80 & 44,05 & & \\
\hline & Faculty of Health Sciences & 48 & 133,10 & 33,59 & & \\
\hline & Faculty of Social Sciences & 45 & 138,24 & 23,60 & & \\
\hline & Faculty of Engineering & 43 & 139,77 & 34,65 & 1,36 & 0,241 \\
\hline \multirow[t]{6}{*}{ Cognitive } & Faculty of Education & 34 & 47,62 & 11,05 & & \\
\hline & School of Physical Education and Sports & 65 & 47,72 & 14,26 & & \\
\hline & Faculty of Arts and Sciences & 30 & 41,93 & 14,37 & & \\
\hline & Faculty of Health Sciences & 48 & 46,69 & 12,72 & & \\
\hline & Faculty of Social Sciences & 45 & 48,42 & 7,44 & & \\
\hline & Faculty of Engineering & 43 & 48,37 & 10,64 & & \\
\hline \multirow[t]{6}{*}{ Affective } & Faculty of Education & 34 & 45,59 & 12,35 & 0,84 & 0,523 \\
\hline & School of Physical Education and Sports & 65 & 45,49 & 14,32 & & \\
\hline & Faculty of Arts and Sciences & 30 & 41,50 & 16,36 & & \\
\hline & Faculty of Health Sciences & 48 & 44,96 & 11,81 & & \\
\hline & Faculty of Social Sciences & 45 & 46,51 & 9,33 & & \\
\hline & Faculty of Engineering & 43 & 47,33 & 11,79 & & \\
\hline \multirow[t]{6}{*}{ Behavioral } & Faculty of Education & 34 & 42,18 & 2,37 & 1,30 & 0,265 \\
\hline & School of Physical Education and Sports & 65 & 43,57 & 1,74 & & \\
\hline & Faculty of Arts and Sciences & 30 & 37,37 & 2,64 & & \\
\hline & Faculty of Health Sciences & 48 & 41,46 & 1,58 & & \\
\hline & Faculty of Social Sciences & 45 & 43,31 & 1,33 & & \\
\hline & Faculty of Engineering & 43 & 44,07 & 2,07 & & \\
\hline
\end{tabular}

Note: $\mathrm{p}>0.05$

According to Table 6 the disparity between the mean attitude scores of the participants with respect to leisure time was not considered statistically relevant in the sense of the faculty variable, according to the one-way Anova test results $(\mathrm{p}>0.05)$.

According to Table 7 , the difference between the attitude score averages of the participants was not statistically significant in the context of the class variable $(\mathrm{p}>0.05)$. Although no difference was observed between any sub-dimension, the behavioral sub-dimension was found to be very close to a significant differentiation $\mathrm{F}$ $(3,261)=2.63, \mathrm{p}=.051$. According to the results of the LSD test applied to test which class groups differ from each other, the behavioral dimension mean scores of the first class (Mean $=45.21, \mathrm{SS}=11.28$ ) according to the behavioral dimension mean scores of the 2 nd grade and 4th grade (respectively; Mean $.=40.20, \mathrm{SS}=12.12$, Avg. $=$ 40.73, SS $=13.87)$ are significantly higher $(\mathrm{p}=.042, \mathrm{p}=.038$, respectively). No significant difference was found among other class groups. 
Table-7. Anova test findings between free time attitude scale and class variable.

\begin{tabular}{l|c|c|c|c|c|c}
\hline Leisure Attitude and Grade & Grade & $\mathbf{n}$ & Mean & sd & F & p \\
\hline Leisure attitude (total) & 1. & 52 & 142,90 & 30,45 & 2,24 & 0,084 \\
\hline & 2. & 54 & 129,91 & 35,20 & & \\
\hline & 3. & 56 & 140,55 & 33,41 & & \\
\hline Cognitive & 4. & 103 & 130,30 & 39,72 & & \\
\hline & 1. & 52 & 49,67 & 10,16 & 1,92 & 0,127 \\
\hline & 2. & 54 & 45,57 & 11,72 & & \\
\hline & 3. & 56 & 48,77 & 11,44 & & \\
\hline Affective & 4. & 103 & 45,67 & 13,37 & & \\
\hline & 1. & 52 & 48,02 & 10,50 & 1,72 & 0,163 \\
\hline & 2. & 54 & 44,13 & 12,80 & & \\
\hline & 3. & 56 & 47,07 & 11,46 & & \\
\hline Behavioral & 4. & 103 & 43,90 & 14,16 & & \\
\hline & 1. & 52 & 45,21 & 11,28 & 2,63 & 0,051 \\
\hline & 2. & 54 & 40,20 & 12,12 & & \\
\hline & 3. & 56 & 44,71 & 11,89 & & \\
\hline
\end{tabular}

As a result, the recreational sports component is found to be important on all leisure attitude scale subdimensions. The sub-dimension with the greatest effect was defined as the sub-dimension of behaviour. Moreover, it has been shown that variables of gender, age, class, and faculty have no major impact on the scale of the leisure attitude. In addition, the effect of the behavioral sub-dimension of the class variable and the cognitive subdimension of the age variable, even if not on the entire scale, was revealed.

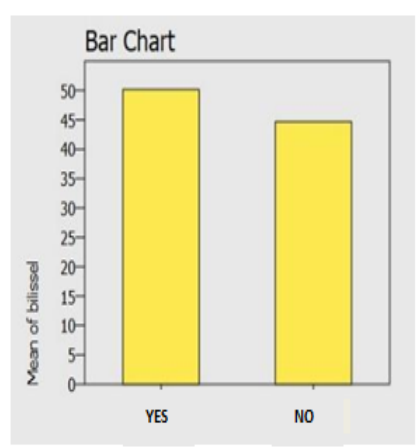

Cognitive Sub-Dimension

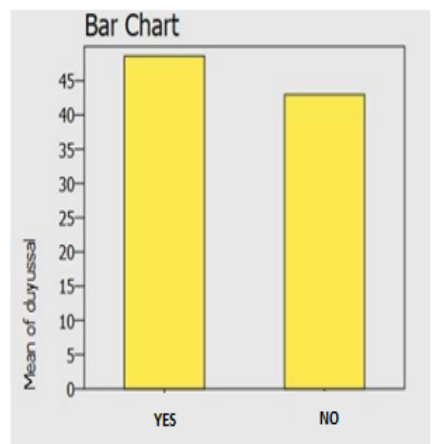

Affective Sulb-Dimension

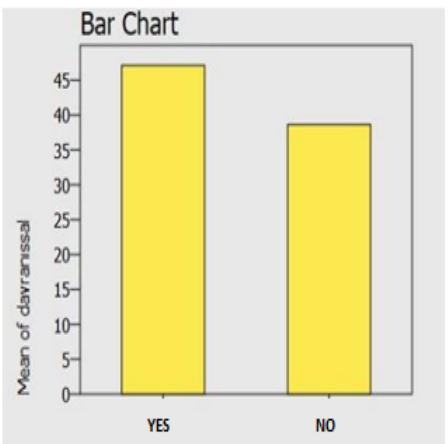

Behavioral Sub-Dimension

Note: Percentage (\%).

Figure-1. Bar graph display of sub-dimensions according to recreative sports.

In Figure 1, leisure time attitude depending on whether or not to do recreative sports. The scale shows how the sub-dimensions differ. The graphs show that each sub-dimension varies for the vector of recreational sports in parallel with the results obtained.

\section{Conclusion}

In this study, the perception of leisure attitudes of the students of Cyprus University was examined. Different results were obtained according to various demographic variables in the study. Accordingly, when the leisure attitudes of study participants were measured according to their age and classes, there was no statistically significant difference between the categories, while in both dimensions there was a discrepancy between the subdimensions. Whereas in the cognitive sub dimension the age variable differentiated, the class variable differentiated in the sub-dimension of the actions. In addition, the recreational attitudes of the participants differed in all subdimensions, depending on the aspect of recreational sports. There was no statistically significant difference between the groups when the leisure attitude and sub-dimensions were evaluated according to gender and faculty component. He explored the attitudes of young people towards their free time in his research by Videnović, Pešić, and Plut (2010). A significant difference was found between leisure time attitudes and sub-dimensions between the sexes. Similar findings were found in the study of Azevedo et al. (2007) leisure attitudes differed significantly between genders. At the same time, according to the analysis findings of Akyuz (2015); Kaya (2011) and McCullough (1993) there is a significant difference in terms of gender for leisure attitudes and sub-dimensions in terms of gender. On the other hand, research stating that there is no statistically significant difference between gender and leisure time attitude takes place in the literature. One of them; the leisure attitudes of the individuals who participated in Pala, Biner, Oncen, and Kargün (2015) research have been mentioned. In 2015, which examined football tennis athletes' attitudes towards leisure activities, they did not differ by gender and did not make any difference in the attitude's 3 sub-dimensions. Also, in the study conducted by Gökyürek (2016) it was stated that there was no statistically significant difference between the leisure time attitude levels and sub-dimensions of the subjects participating in the study and their gender. In another study, Akgül (2011) evaluated the attitudes of individuals from different cultures to leisure activities, while there was no difference between leisure time and gender variable of individuals living in London, while men participating in the research between leisure time and gender variable of individuals living in Ankara, there was a difference in terms of higher leisure attitudes than women.

The divulgation of significant variations is found by examining the analyzes between age and leisure time. Unlike the findings obtained during Deng, Walker, and Swinnerton (2005) study. No major differences in the 
cognitive and affective sub-dimensions in terms of age levels were recorded during 2005. Similar findings were obtained by Gökyürek (2016) demonstrating that there was no significant difference between the age variable and leisure attitudes. In the study conducted by Celik (2014) it was observed that there was a cognitively and affectively significant difference in the age of students and leisure attitude sub-dimensions of the police college students who participated in the study, but there was no statistically significant difference in the behavioral dimension.

As a result, it was determined that certain factors expose relationships and differences with the leisure attitude, while at the same time engaging in leisure activities is an efficient means of recreation. It was observed that the attitude levels of the sample group in the study were high, and that certain variables differentiated that amount. The study can be tested on various sample groups and findings can be extended on the attitude of leisure time.

\section{References}

Akgül, B. M. (2011). Evaluation of attitudes of individuals from different cultures towards leisure activities: Ankara-London example. Gazi University Institute of Health Sciences, Ph.D. Thesis, Ankara.

Akgül, B. M., \& Gürbüz, B. (2011). Leisure attitude scale: Validity and reliability study. Gazi Journal of Physical Education and Sports Sciences, $16(1), 37-43$.

Akyuz, H. (2015). Examining the attitudes of university students towards leisure activities - the case of Bartın University. Bartın University Institute of Educational Sciences Master Thesis, Bartin.

Andersen, L. B., Schnohr, P., Schroll, M., \& Hein, H. O. (2000). All-cause mortality associated with physical activity during leisure time, work, sports, and cycling to work. Archives of Internal Medicine, 160(11), 1621-1628.Available at: https://doi.org/10.1001/archinte.160.11.1621.

Azevedo, M., Araújo, C., Reichert, F., Siqueira, F., Silva, M., \& Hallal, P. (2007). Gender differences in leisure-time physical activity. International Journal of Public Health, 52(1), 8-15.

Berg, B. K., Warner, S., \& Das, B. M. (2015). What about sport? A public health perspective on leisure-time physical activity. Sport Management Review, 18(1), 20-31.

Celik, Z. (2014). Investigation of Ankara police college students' attitudes towards leisure activities. Gazi University Health Sciences Institute, Master Thesis, Ankara.

Deng, J., Walker, G. J., \& Swinnerton, G. (2005). Leisure attitudes: A comparison between Chinese in Canada and Anglo-Canadians. Leisure, 29(2), 239-273.

George, D., \& Mallery, P. (2010). SPSS for windows step by step: A simple guide and reference 17.0 update (10th ed.). Boston: Pearson.

Gökyürek, B. (2016). An analysis of leisure attitudes of the individuals participating in dance activities and the relationship between leisure attitude and life satisfaction. International Journal of Environmental and Science Education, 11(10), 3285-3296.

Hagger, M. S., Chatzisarantis, N. L., Culverhouse, T., \& Biddle, S. J. (2003). The processes by which perceived autonomy support in physical education promotes leisure-time physical activity intentions and behavior: A trans-contextual model. Journal of Educational Psychology, 95(4), 784-795.Available at: https://doi.org/10.1037/e547922012-136.

Kaya, A. M. (2011). Investigation of university students' attitudes towards recreational activities and leisure motivations in terms of some variables. Master's Thesis, Sivas Cumhuriyet University / Institute of Health Sciences, Sivas.

Kim, B. H., Newton, R. A., Sachs, M. L., Giacobbi, P. R., \& Glutting, J. J. (2011). The effect of guided relaxation and exercise imagery on selfreported leisure-time exercise behaviors in older adults. Journal of Aging and Physical Activity, 19(2), 137-146.Available at: https://doi.org/10.1123/japa.19.2.137.

Lee, D.-c., Pate, R. R., Lavie, C. J., Sui, X., Church, T. S., \& Blair, S. N. (2014). Leisure-time running reduces all-cause and cardiovascular mortality risk. Journal of the American College of Cardiology, 64(5), 472-481.Available at: https://doi.org/10.1016/j.jacc.2014.04.058.

Maeda, J. K., \& Randall, L. M. (2003). Can academic success come from five minutes of physical activity? Brock Education: A Journal of Educational Research and Practice, 13(1).Available at: https://doi.org/10.26522/brocked.v13i1.40.

Marshall, G. (1999). Dictionary of sociology. Akınhay O, Kömürcü D (Cev) (1st ed.). Ankara: Science and Art Publications.

McCullough, J. (1993). Women, men, and time: Gender differences in paidwork, housework, and leisure. The Journal of Consumer Affairs, $27(2), 430-433$

Momenan, A., Delshad, M., Mirmiran, P., Ghanbarian, A., \& Azizi, F. (2011). Leisure time physical activity and its determinants among adults in Tehran: Tehran lipid and glucose study. International Journal of Preventive Medicine, 2(4), 243-251.

Ozdemir, A. S. (2020). Serious leisure perspectives in sports: Professional athletes' career progress via serious leisure. Asian Journal of Education and Training, 6(2), 186-195.Available at: https://doi.org/10.20448/journal.522.2020.62.186.195.

Ozdemir, A. S., \& Ayyıldız Durhan, T. (2020). Understanding flow experiences in professional athletes. European Journal of Education Studies, $7(2), 155-171$

Ozdemir, A. S. (2020a). Exploring intrinsic leisure motivations of University students. Online Submission, 7(1), 52-65.

Pala, A., Biner, M., Oncen, S., \& Kargün, M. (2015). Examination of football tennis athletes' attitudes towards leisure activities. International Journal of Sports, Exercise and Training Science, 1(2), 77-82.

Ragheb, M. G., \& Beard, J. G. (1982). Measuring leisure attitude. Journal of Leisure Research, 14(2), 155-167.Available at: https://doi.org/10.1080/00222216.1982.11969512.

Rodgers, W. M., \& Gauvin, L. (1998). Heterogeneity of incentives for physical activity and self-efficacy in highly active and moderately active women exercisers. Journal of Applied Social Psychology, 28(11), 1016-1029.Available at: https://doi.org/10.1111/j.15591816.1998.tbo1665.x.

Rovio, S., Kåreholt, I., Helkala, E. L., Viitanen, M., Winblad, B., Tuomilehto, J., \& Kivipelto, M. (2005). Leisure-time physicalactivity at midlifeandthe risk of dementiaand Alzheimer'sdisease. The Lancet Neurology, 4(11), 705-711.

Ruffault, A., Bernier, M., Juge, N., \& Fournier, J. F. (2016). Mindfulness may moderate the relationship between intrinsic motivation and physical activity: A cross-sectional study. Mindfulness, 7(2), 445-452.Available at: https://doi.org/10.1007/s 12671-015-0467-7.

Sheriff, M., \& Sheriff, C. (1996). Introduction to social psychology II. Atakay M, Yavuz A Trans (1st ed.). Istanbul: Social Publications.

Sindik, J., Andrijasevic, M., \& Curkovic, S. (2009). Relation of student attitude toward leisure time activities and their preferences toward sport recreation activities. Acta Kinesiologica, 3(1), 54-58.

Teaff, J. (1975). An elderly leisure attitude schedule. Paper presented at the 28th Annual Meeting of the GerontologicalSociety. Oct 26-30. Louisville, Kentucky.

Videnović, M., Pešić, J., \& Plut, D. (2010). Young people's leisure time: Gender differences. Psychology, 43(2), 199-2 14. 